\title{
THE ROLE OF BASE PLATE TEMPERATURE OF HDPE SHEET TENSILE STRENGTH AND IMPACT ON HOT GAS WELDING
}

\section{AGUS SETIAWAN, YUNIATO AGUS W, DAN SYAMSUL HADI \& SUGENG HADI SUSILO}

Department Mechanical Engineering, Politeknik Negeri Malang

\section{ABSTRACT}

Plastic material failures such as fractures or cracks can be repaired by joining. In the industrial world, the joining of two or more plastic parts can be done with plastic welding technology, one of the methods of plastic welding is hot-gas welding (HGW). HGW is a welding process for plastic materials, but it is known that plastic materials have poor heat conductivity. The research objective was to determine the role of the foundation plate temperature on the tensile strength and the impact on HDPE sheet welding using hot gas welding. The method uses the hot gun setting and the base plate temperature during the welding process $\left(30^{\circ} \mathrm{C}, 60^{\circ} \mathrm{C}, 90^{\circ} \mathrm{C}\right.$ and $\left.120^{\circ} \mathrm{C}\right)$, as well as the hot air flow temperature of the hot gun $\left(250^{\circ} \mathrm{C}, 300^{\circ} \mathrm{C}\right.$, and $350^{\circ} \mathrm{C}$ ). To obtain data, it was carried out by tensile and hit tests using standard specimens, respectively ASTM D 638-03 and ASTM D 6110. The results of research, it was found that the temperature of the foundation plate and the temperature of hot gun hot air flow during the hot gas welding process had an effect on the tensile strength and the hit of the HDPE welding

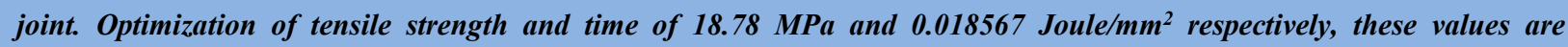
obtained from the combination of an anvil plate temperature of $120^{\circ} \mathrm{C}$ and hot hot air flow of $200^{\circ} \mathrm{C}$.

KEYWORDS: HDPE Sheet, Hot Gas Welding, Strength, Tensile Welding, Base Plate

Received: Oct 04, 2020; Accepted: Oct 24, 2020; Published: Nov 23, 2020; Paper Id.: IJMPERDOCT202059

\section{INTRODUCTION}

Plastic material failures such as fractures or cracks can be repaired by joining. The connection of two or more plastic material parts can be done using a plastic welding technology. One of the plastic material welding technologies that has been developed in the mid-20th century is hot gas welding (HGW) [1].

Plastic welding can be said to be good if the characteristics of the welded joint and its homogeneity are close to the characteristics of the seamless plastic material, but the mechanical strength of the welding results, namely the welded joints, generally has a value that is still lower than the mechanical strength of the material without welding [2], [3].

The hot gas welding method is the most reliable and technically profitable from a research and production point of view [4]. In order to avoid defects/damage and increase the mechanical properties of the material to be welding using the preheating process, where the preheating process aims to stabilize the specimen temperature before welding [5]- [6].

The use of a heated anvil plate that is placed on the bottom surface of the HDPE sheet to be welded, where the heating value can be adjusted before and during the fsw friction stir welding process) can increase the tensile strength and homogeneity of the HDPE sheet weld joints [6]-[8].

The heater on the foundation plate will provide heat to the material which is precisely around the area of the weld 
joint (HAZ), and the heat from the heater is controlled stably at a certain temperature before and during the hot gas welding process [9]-[10].

\section{MATERIAL AND METHOD}

This study was to determine the role of the foundation plate temperature on the dance strength and impact of HDPE sheet welds on hot gas welding.

The research method used variations in the temperature of the anvil plate during the welding process $\left(30^{\circ} \mathrm{C}, 60^{\circ} \mathrm{C}\right.$, $90^{\circ} \mathrm{C}$ and $\left.120^{\circ} \mathrm{C}\right)$, as well as the hot air flow temperature of the hot gun $\left(250^{\circ} \mathrm{C}, 300^{\circ} \mathrm{C}\right.$, and $\left.350^{\circ} \mathrm{C}\right)$. To obtain data, it was carried out by tensile and hit tests using standard specimens, respectively ASTM D 638-03 and ASTM D 6110 [12]-[13].

The welding process is carried out by placing the HDPE sheet on the jig then adjusting the base plate temperature and the hot-gas temperature according to the predetermined level. Figure 1 shows a plate Jig, while the welding process is carried out as shown in figure 2 with a welding position of $1 \mathrm{G}$ [11].

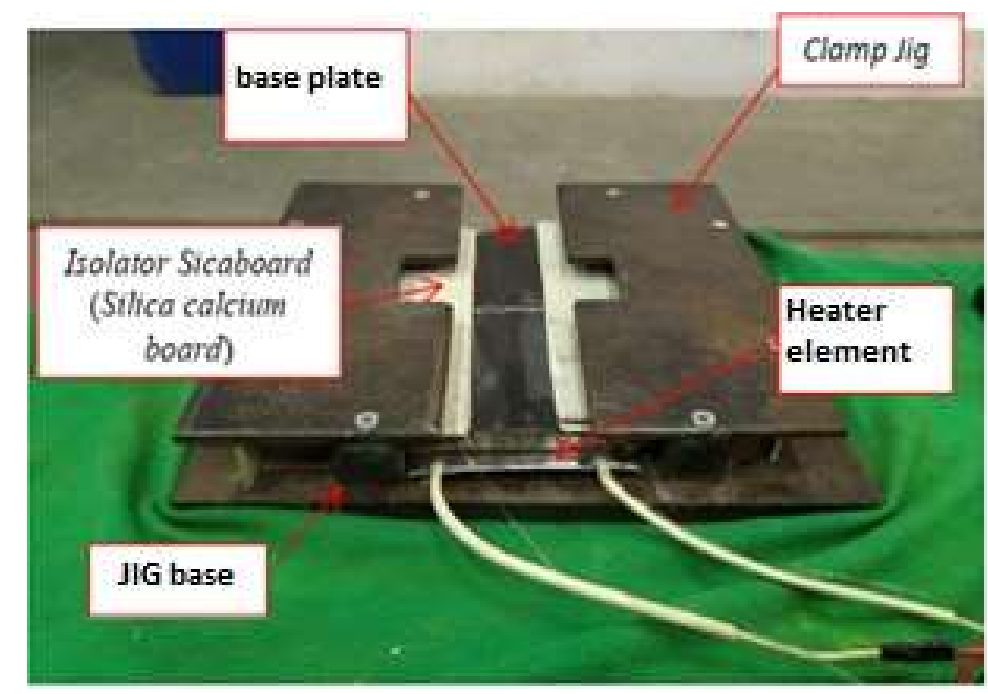

Figure 1: Plate jig

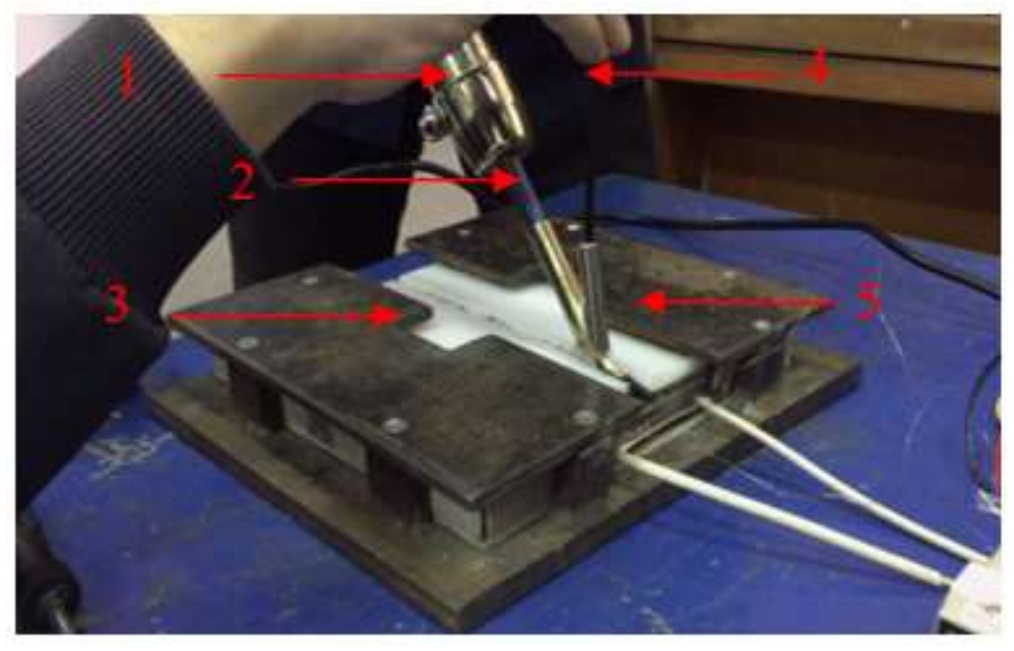

Figure 2: Set up of the welding process 
Where, 1. Hot-Gun. 2.HDPE sheet, 3.Jig, 4. Filler, 5, Heating plate. Specimen standard, tensile test using ASTM D 638-03 type II standard (ASTM, 2016). After performing the pull and hit test using and ASTM D 6110.

\section{RESULT AND DISCUSSIONS}

Figure 3 shows the results of the tensile test of HDPE sheet weld joint specimens in each treatment, while Figure 4 shows the impact test of HDPE sheet weld joints in each treatment.

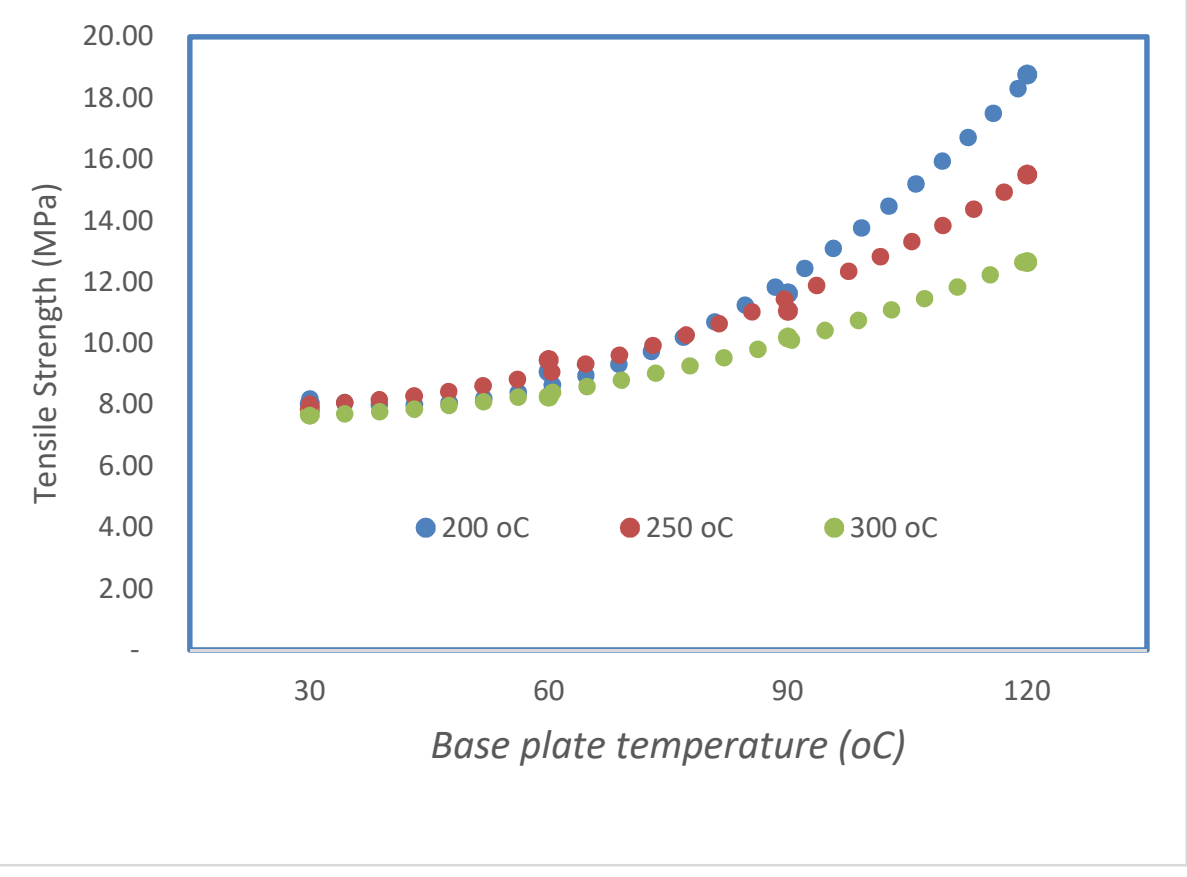

Figure 3: Tensile Strength of HDPE Sheet Welds at various base plate temperatures.

Figure 3 shows that the base plate temperature and hot-gas temperature have a significant effect on tensile strength, this is shown that the higher the hot gas temperature causes the lower tensile strength value. Conversely, the higher the temperature of the foundation plate, the higher the tensile strength value. At $120 \mathrm{oC}$, the temperature of the foundation plate indicates that the higher the hot-gas temperature, the lower the tensile strength of the weld joint. This is due to the fact that HDPE material is given a temperature above $200 \mathrm{oC}$, which causes the atomic bonds of its constituents to move away, thereby weakening the tensile strength of HDPE plastic. This means that heating above $200 \mathrm{oC}$ results in further bonds between the constituent atoms, if cooling is too fast, then the molecular strength remains at a distance. This results in the weakening of the tensile strength of this plastic material. 


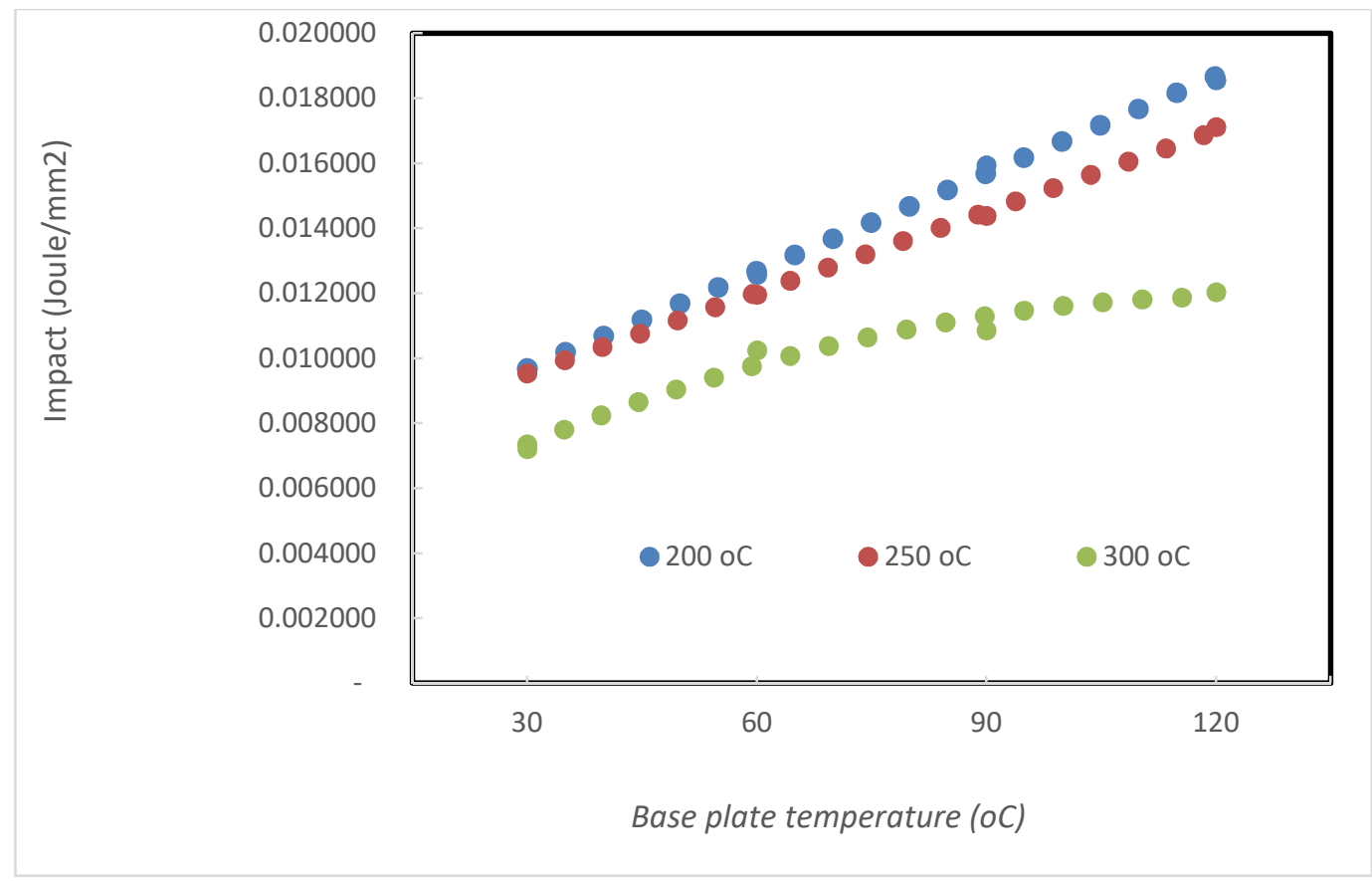

Figure 4: Impact strength of HDPE Sheet Welds at various base plate temperatures.

Figure 4 shows that the base plate temperature and hot gas temperature have a significant effect on the impact strength of the HDPE weld joint. The higher the hot gas temperature, the lower the impact strength value. And conversely, the higher the temperature of the foundation plate, the higher the value of the hit strength. In addition, the higher the hotgas temperature, the higher the impact strength of the weld joint. On the red line where the temperature value of the foundation plate is $120 \mathrm{oC}$, the higher the hot-gas temperature value, the higher the impact strength value of the weld joint. Along with the results of the tensile strength test, the impact strength is almost the same. This is due to the fact that HDPE material is given a temperature above $200 \mathrm{oC}$, which causes the atomic bonds of its constituents to move away, thus weakening the impact strength of HDPE plastic. This means that heating above $200 \mathrm{oC}$ results in further bonds between the constituent atoms, if cooling is too fast, the molecular bonds remain at a distance. This results in the weakening of the impact strength of this plastic material. 


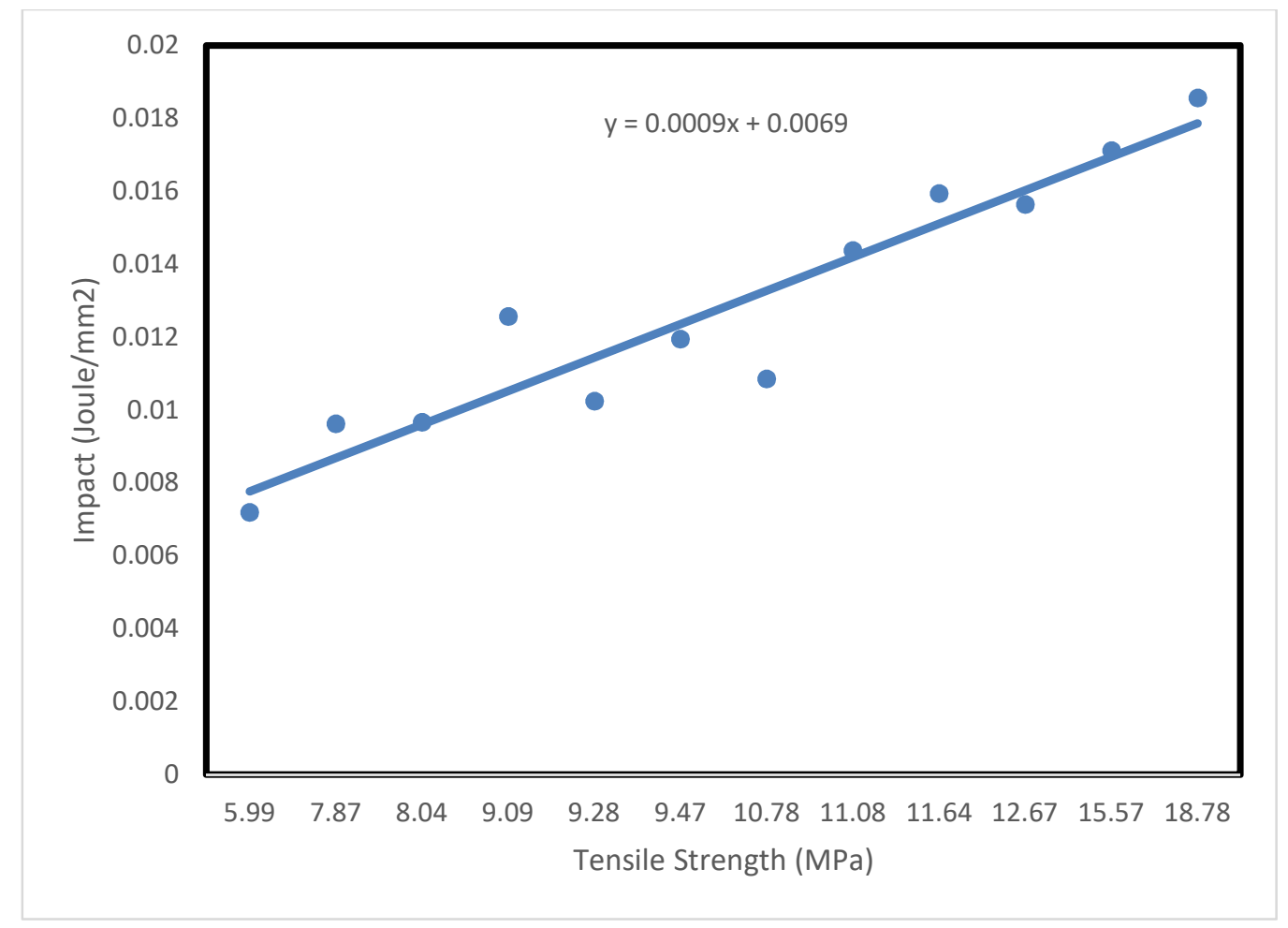

Figure 5: Relationship between Tensile Strength and Impact of Welded HDPE Sheet.

Figure 5 shows that with the increase in the tensile strength value of the HDPE sheet weld joint the strength value of the HDPE weld joint also increases. The relationship between the tensile strength and the hit strength of the HDPE sheet weld joint is expressed in a linear trendline graph with the equation $y=0.0009 x+0.0069$. While the optimization of tensile strength and time of $18.78 \mathrm{MPa}$ and $0.018567 \mathrm{~J} / \mathrm{mm} 2$, respectively, the value is obtained from a combination of an anvil plate temperature of $120^{\circ} \mathrm{C}$ and a hot air flow of $200^{\circ} \mathrm{C}$.

\section{CONCLUSIONS}

The conclusions that can be obtained from the research that has been done are as follows:

- The temperature variation of the foundation plate during the hot gas welding (HGW) process affects the strength characteristics of the HDPE sheet weld joint. The strength characteristics of the weld joint which include the tensile strength and the hit strength show that the higher the temperature of the foundation plate, the higher the tensile strength and the impact strength of the weld joint.

- The temperature variation of hot gun hot air flow during the hot gas welding (HGW) process affects the strength characteristics of the HDPE sheet welding joint. The strength characteristics of the weld joint which include the tensile strength and the hit strength show that the higher the temperature of the hot gun hot air flow, the lower the tensile strength and the impact strength of the weld joint.

- The characteristics of the best (optimum) HDPE sheet weld joint strength including tensile strength and impact strength are $18.78 \mathrm{MPa}$ and $0.018567 \mathrm{~J} / \mathrm{mm} 2$, respectively. This value is obtained from the combination of an anvil plate temperature of $120^{\circ} \mathrm{C}$ and a flow of hot hot air of $200^{\circ} \mathrm{C}$. 


\section{REFFERENCES}

1. A. Thakur1, H. Gebrelibanos, and T. Gabrey, “Arc Welding Process Selection through a Quality and Costs, ” Int. J. Curr. Eng. Technol., vol. 9, no. 03, 2019, doi: 10.14741/ijcet/v.9.3.6.

2. G. Dwi Winarto, R. Wardhani, and I. Syarif, "Analysis of Buttering Method on Mechanical Properties Welded Material Low Carbon Steel," IPTEK J. Proc. Ser., vol. 0, no. 1, 2014, doi: 10.12962/j23546026.y2014i1.386.

3. S. H. Susilo and Z. Jannah, "Effect of Electrodes, Electric Currents, And Nahco 3 Concentration Against Hho Pressure Generator," vol. 10, no. 4, pp. 1-3, 2020.

4. M. S. Khaliel Youssif, M. A. El-Sayed, and A. E. F. M. Khourshid, "Influence of critical process parameters on the quality of friction stir welded nylon 6," Int. Rev. Mech. Eng., vol. 10, no. 7, pp. 501-507, 2016, doi: 10.15866/ireme.v10i7.9690.

5. S. H. S. et al. . Sugeng Hadi Susilo et al., "The Effect of Cyclone Surface Area towards Engine Performance, Intake Manifold Pressure and Exhaust Gas Emission," Int. J. Mech. Prod. Eng. Res. Dev., vol. 10, no. 3, pp. 13721-13730, 2020, doi: 10.24247/ijmperdjun20201307.

6. H. L. Steels and V. Marjanovi, "applied sciences Analysis of Influence of the Welding Procedure on Impact Toughness of Welded Joints of the, " 2020.

7. M. S. Y., "a Review of Effect of Welding and Post Weld Heat Treatment on Microstructure and Mechanical Properties of Grade 91 Steel,” Int. J. Res. Eng. Technol., vol. 04, no. 03, pp. 574-580, 2015, doi: 10.15623/ijret.2015.0403096.

8. S. H. Susilo, A. Dani, and U. M. I. A. Roisatin, “The Role Of The Hydrocarbon Cracking System On Gas Emissions,” vol. 10, no. 3, pp. 16405-16412, 2020.

9. S. Ingle and M. J. Deshmukh, "Parametric Analysis of Hot Gas Welding for PP+EPR Blend and Evaluation of Welds in Tensile Conditions," Int. J. Innov. Sci. Res. Technol., vol. 5, no. 6, pp. 335-339, 2020, doi: 10.38124/ijisrt20jun445.

10. Setiawan, A., Irawan, Y., \& Purnowidodo, A. (2011). Pengaruh Temperatur Pelat Landasan Selama Proses Friction Stir Welding Terhadap Kekuatan Tarik Sambungan Las Lembaran HDPE. Rekayasa Mesin, 2 (3), 232-240.

11. E. Abdel-Gwad, A.-B. Omar, and A. Radwan, "Loadability of Friction Stir Welded joints of High Density Polyethylene," PortSaid Eng. Res. J., vol. 19, no. 1, pp. 100-107, 2015, doi: 10.21608/pserj.2015.36763.

12. ASTM International. (2010). Standard Test Method for Determining the Charpy Impact Resistanc of Notched Specimens of Plastic ASTM D6110.

13. ASTM International E3-95. (2016). Standart Practice of Preparation of Metallografphic Specimen. 82 (C), $1-15$. http://doi.org/10.1520/D0638-14.1 